\title{
1. Introduction: Replacing the standard algorithm for environmental law
}

It is a general historic fact about Western civilizations that they traditionally turn to law and legal institutions to assist their societies undergoing social and economic change. When seeking to accomplish cultural or societal goals during a time of change, laws typically follow the particular interests of the people wishing to achieve the goal. So, during the 19th and 20th centuries, when the United States was becoming an industrial power to be reckoned with, American laws furthered and made possible the idea of economic growth. These laws did not just passively respond to the needs of a growing economy; lawmakers actively and aggressively ensured that relevant common and statutory law changed to help bring about the conditions necessary to create a strong and robust, economically-oriented market-based social structure. ${ }^{1}$

By the middle of the 20th century, neither policymakers nor the public could escape the fact that our obsession with economic growth, fueled by natural resources development, was creating obvious social costs in the form of air and water pollution, toxic waste poisoning of the land, and serious alterations of the Earth's natural environment. ${ }^{2}$ Again, we turned to law and legal institutions for help. This time we sought to use legal institutions, like statutes, to address these human-caused "harms" to natural landscapes and environmental goods. ${ }^{3}$

This belief in the curative and restorative power of law led to the creation of an expansive, complicated body of law known as "environmental law." This newly established body of law now exists in the United States, Great Britain, the EU, Australia, and virtually every Western nation. These laws are

1 See James Willard Hurst, Law and the Conditions of Freedom in the Nineteenth-Century United States (1956); James Willard Hurst, Law and Social Order in the United States (1977); James Willard Hurst, Law and Economic Growth: The Legal History of the Lumber Industry in Wisconsin, 1836-1915 (1965).

2 L. White, The Historical Roots of Our Ecological Crisis, 155 Science 1203 (1967); Gilbert F. White, Reflections on Changing Perceptions of the Earth, 1994 Annual Review of Energy and the Environment 19 (1993).

3 A. Dan Tarlock, A History of Environmental Law, in Vol. I Environmental Laws and Their Enforcement (2009); Z.J.B. Plater, From the Beginning, A Fundamental Shift in Paradigms: A Theory and Short History of Environmental Law, 27 Loyola Los Angeles L. Rev 981 (1994). 
enforced by government managers and agencies that in turn make even more rules. All this environmental law has one primary purpose, which is to ensure that present and future generations might enjoy the benefits of a "healthy" environment on Earth. ${ }^{4}$

Unfortunately, by the 21 st century, we had realized that human actions had gone beyond air pollution and the poisoning of lands and water bodies; our accelerating pace of fossil fuel energy use, greenhouse gas emissions, and population growth had thrust the planet itself into a massive uncontrolled experiment. Anthropomorphic actions had modified the Earth itself, along with Earth's natural systems and natural resources. Humans were influencing global ecology and the planet's biosphere that permit the species homo sapiens to survive. Climate change threatened the Earth's normally stable global temperature, melting polar and Antarctic ice and permafrost, and releasing greenhouse gases locked in the frozen Earth. ${ }^{5}$

Environmental lawmakers responded, once again, to these global threats to the natural environment by adopting even more laws and regulatory schemes. But, to no avail. By the first two decades of the 21 st century, the general consensus was that humans had dramatically altered the planet's biogeochemical systems. Human activity seeking global economic growth had become the primary driver of change in the "Earth System" - the sum of the planet's interacting physical, chemical, biological, and human processes. Each global indicator of changes in the Earth System showed that the changes were not linear, but exponential. There was a "Great Acceleration" in both human activity and subsequent alterations of the Earth Systems. This acceleration could be measured in the increasing amounts of:

- carbon dioxide;

- nitrous oxides;

- methane gas;

- stratospheric ozone;

- $\quad$ surface temperature;

- ocean acidification;

- marine fish capture;

- coastal nitrogen;

- tropical forest loss;

- general deforestation;

- domesticated, non-“"natural," landscapes;

4 R. Percival, C. Schroeder, Alan Miller, and J. Leape, Environmental Regulation: Law, Science, and Policy I (8th ed. 2018).

5 Intergovernmental Panel on Climate Change, IPCC Special Report on Climate Change and Land, https://www.ipcc.ch (2019). 
- extinctions and loss of species;

- ecosystem loss;

- terrestrial biosphere degradation. $^{6}$

Indeed, this anthropocentric alteration of the Earth's biosphere and ecosystems became so transformative that it was generally accepted that the planet had entered a new era - the Anthropocene. ${ }^{7}$ This new era is unlike the eras that preceded it. It did not come about by some external cause, like a giant asteroid striking the Earth, or the eruption of a chain of supervolcanoes. This Anthropocene Era was caused by anthropogenic actions. And this current era, unlike previous ones, threatens the future of life, and certainly human life, on Earth. $^{8}$

What is particularly paradoxical and alarming about this dire forecast is that these environmental concerns are not arising because lawmakers have been paralyzed or reluctant to address the obvious need to do something. To the contrary, a vast array of environmental laws has been enacted in direct response to the fears of scientists and the public about the deteriorating condition of the Earth's natural environment. There is now, in the United States and elsewhere, an expansive, complicated body of law intended to correct behaviors causing environmental problems, so that present and future generations might enjoy the benefits of a "healthy" environment on Earth. These environmental laws constitute an elaborate network of statutes, regulations, orders, and case law that is enforced by multiple layers of national, regional, state, and local bureaucracies.

Despite this impressive outpouring of lawmaking, the reality is that today's environmental laws have "proven insufficient to deal with current challenges,"

6 Susan Callery and Daniel Bailey, NASA: Climate Change and Global Warming (Oct. 29, 2020); John Branch and Brad Plumer, Climate Change is Now Locked In: The Next Moves Will Be Crucial, The New York Times (Sept. 22, 2020); John Schwartz, How Much Will the Planet Warm if Carbon Dioxide Levels Double?, The New York Times (July 22, 2020); J.R. McNeill and Peter Engelke, The Great Acceleration: An Environmental History of the Anthropocene Since 1945 (2016).

7 Paul Crutzen, Geology of Mankind, 415 Nature 23 (2002).

8 Tom Matthews and Colin Raymond, Global Warming Now Pushing Heat into Territory Humans Cannot Tolerate, The Conversation (May 20, 2020); Aritz Parra and Frank Jordans, Climate Change Conference, U.N. Chief Warns of "Point of No Return," The Associated Press (Dec. 2, 2019); Kelsey Piper, Is Climate Change an "Existential Threat" - or Just a Catastrophic One? The debate over whether climate change will end life on Earth, https://www.vox.com/future-perfect (2019); Anders Sandberg, Will Climate Change Wipe Out Humanity?, Newsweek (May 31, 2019); Climate Scientists to World: We Have Only 20 Years Before There's No Turning Back, https://www.nrdc .org/onearth/climate (2018) (summarizing report by the Intergovernmental Panel on Climate Change (2018)). 
and are "not up to coping with the larger challenges ahead." The evidence is unassailable. Although our environmental laws are intended to ensure a healthy Earth environment for its human inhabitants, scientists overwhelmingly agree that the Earth may soon be uninhabitable for homo sapiens. ${ }^{10}$

An Earth unfit for humans is due to humans. Humans have produced catastrophic climate change, ${ }^{11}$ global warming, ${ }^{12}$ mass extinctions, ${ }^{13}$ and deadly alterations of Earth's natural systems. ${ }^{14}$

The inability of environmental laws to solve these problems of the Anthropocene is not because these problems are unsolvable or intractable. Environmental laws fail because they rely on a flawed algorithm. An algorithm is a set of rules and instructions to be followed that, given an initial set of conditions or assumptions, will solve a problem. The algorithm for most environmental laws and proposals for environmental laws wrongly presumes that separation is the central defining characteristic for environmentalism. The standard algorithm for solving our environmental problems with laws is centered around a mistaken belief (which has become a condition to the algorithm) that there is, and there should be, a separation between (1) the components of the natural world, (2) humans and nature, (3) humans and humans, (4) science and environmental policies, (5) environmental laws and the humans subject to these laws, and (6) environmental laws and nature. Environmental laws will succeed, and environmental problems will be solved, only when

9 James Gustave Speth, The Bridge at the End of the World 9 (2008). See also Parra and Jordans, supra note 8 (U.N. Secretary General stating that "the world's efforts to stop climate change have been utterly inadequate"); Jan Laitos, Why Environmental Policies Fail 9-10 (Cambridge University Press 2017). See generally Chapter 6, infra.

10 David Wallace-Wells, The Uninhabitable Earth: Life After Warming (2019); Mike Berners-Lee, There is No Planet B (2019).

11 Somini Sengupta, Climate Change: Report Warns of March to Catastrophe, The New York Times (Nov. 27, 2019); Intergovernmental Panel on Climate Change (IPCC), Climate Change and Land (Aug. 2019).

12 Seth Borenstein, Earth Had its Hottest Decade on Record, Associated Press (Jan. 16, 2020); 2019 Concludes a Decade of Exceptional Global Heat and High-Impact Weather, United Nations World Meteorological Organization (Dec. 3, 2019); Climate Scientists to World: We Have Only 20 Years Before There is No Turning Back, www .nrdc.org/onearth (April 10, 2019).

13 Will Humans Survive the Sixth Great Extinction? National Geographic (Nov. 9, 2018).

14 James Hamblin, We Are Running Out of Air, The Atlantic (Nov. 6, 2019); Justin Gillis, Our Climate Future Has Arrived: We Ignored Warnings of Wildfire, Flooding, Heat Waves, and Rising Oceans, The New York Times (Oct. 13, 2019); Will Steffen, et al., Trajectories of the Earth System in the Anthropocene, Proceedings of the National Academy of Sciences (June 8, 2018). 
this separation-based algorithm is replaced with one based on connection and entanglement.

What follows in this book is a story of how traditional assumptions involving nature, humans, science, and policy produced a body of environmental laws built with an algorithm grounded in separation. These laws have largely failed to protect an environment on this planet that is the only known location in the universe that can sustain life. This failure calls for a rethinking of (1) standard responses to environmental issues, and even (2) innovative and creative suggestions, often by academics and policymakers, such as the "Green New Deal" advanced by members of the U.S. Congress. ${ }^{15}$ The new algorithm offered here is therefore unlike other calls for "new approaches to environmental lawmaking" that simply make alterations to that historic, but flawed, lawmaking formula. If the prevailing algorithm for our environmental laws is wrong, proposals that remain derivative of that defective environmental formula will similarly fail. What is needed is to replace that algorithm with one that is based on an entirely different set of assumptions.

One of the first prevailing assumptions that needs to be reconsidered involves the proper role in science in the development of environmental policy. Instead of science being limited to "what-is" questions, its role should be expanded so that it is linked to "what-ought-to-be" policy issues. Such a science-based algorithm for environmental law would be grounded not in separation, but in connection between science and policy. A new algorithm would recognize that the parts of the natural world are interconnected, just as there is an interconnection between humans and nature, and humans and humans. Instead of there being a gap between science and policy, this new algorithm would presume that policy should directly flow from science, albeit a perception of science ("explanatory" science) that is quite broader than how we have previously viewed science ("utilitarian" science).

Other popular assumptions would be transformed by a new and different algorithm. A completely revised algorithm would yield environmental policy that is less dogmatic, and more pragmatic. For example, social planners and lawmakers should not issue orders telling regulated humans what not to do. Rather, environmental laws should feature feedback loops among those subject to the laws, which in turn encourage, but do not command, people to do acts and to affirmatively make choices, consistent with environmental goals. Also, instead of top-down commands by legislatures and agencies armed with vast rulemaking powers, law-backed environmental choices should be bottom-up, initiated by people and the demands of nature, not by an enormous bureaucratic apparatus. Moreover, environmental rules should not be complex

$15 \mathrm{http}: / /$ www.congress.gov/bill/116th-congress/house resolution/109/text 
and complicated, requiring layers of administrative enforcement and endless post-hoc judicial interpretation. Environmental laws consistent with the new algorithm would be simple, and faithful to a near irrefutable presumption that less is, indeed, more.

More important, the new algorithm realizes that environmental laws directed at humans must themselves reflect, and be connected to, natural laws that appear to govern the natural environment. Our positive laws addressing the workings of the natural environment must also conform to the immutable, universal Laws of Nature.

In short, our environmental laws about nature need to be consistent with the Laws of Nature. Those universal Laws of Nature stem from three science-based principles that scientists, physicists, and empiricists have observed everywhere in the universe: (1) environmental entanglement and (2) environmental economy and (3) symmetry. Entanglement and economy and symmetry seem to guide the operation of the universe, and so too should they guide environmental laws.

We should not merely modify the algorithm for environmental law. We should rewrite it to be consistent with those three fundamental Laws of Nature. The chapters in this book propose a new policy paradigm that has a better chance of success, compared with past and present and proposed policies. By following the larger forces of the universe and the natural environment, environmental law can bring about changes that will permit humans to survive in Earth's biosphere. 